\title{
Comparative Thermometery in Paediatric Age Group: Is the Non-Touch Infrared Thermometer (NTIT) Reading Comparable to Regular Mercury-in-Glass Thermometer (MIGT) Reading?
}

\author{
Yetunde Olasinde1, Moninuola Ernest ${ }^{2}$, Gbenga Popoola1, Kolade Ernest ${ }^{*}$ \\ ${ }^{1}$ Department of Paediatrics, University of Ilorin Teaching Hospital, Ilorin, Nigeria \\ ${ }^{2}$ Department of Dental Surgery, University of Ilorin Teaching Hospital, Ilorin, Nigeria \\ Email: *kolade.ernest@gmail.com
}

How to cite this paper: Olasinde, Y., Ernest, M., Popoola, G. and Ernest, K. (2018) Comparative Thermometery in Paediatric Age Group: Is the Non-Touch Infrared Thermometer (NTIT) Reading Comparable to Regular Mercury-in-Glass Thermometer (MIGT) Reading? Open Journal of Pediatrics, 8, 303-310.

https://doi.org/10.4236/ojped.2018.84031

Received: August 30, 2018

Accepted: November 12, 2018

Published: November 15, 2018

Copyright $\odot 2018$ by authors and Scientific Research Publishing Inc. This work is licensed under the Creative Commons Attribution International License (CC BY 4.0).

http://creativecommons.org/licenses/by/4.0/

\begin{abstract}
Background: Accurate temperature measurement is a critical step in evaluating health or disease especially in children and immmunocompromised subjects; inaccurate measurement may lead to improper diagnosis, wrong treatment or inappropriate intervention. Several methods of temperature measurements exist and comparing these gives room for choosing a near ideal method in terms of speed, safety and accuracy. The study aimed to compare the forehead non touch infra-red thermometer with the axillary mercury-in-glass method of temperature measurement in the Paediatric age-group. Methods: Study was given ethical approval as part of a larger study. Four hundred and thirty seven children aged 1 to 24 months were studied at the well-baby/immunizationclinic of the University of Ilorin Teaching Hospital over a 6-months period. Both non-touch infrared and theregular mercury-in-glass thermometers were used to take the body temperatures. Data were analysed with SPSS version 21. Pearson correlation was used to determine the relationship between the two methods of temperature measurements, while Bland-Altman method was used to test for level of agreement between them. Results: The mean age and SD was $5.81 \pm 4.04$ months. Pearson correlation showed a positive correlation between the axillary mercury-in-glass and forehead non-touch infra-red thermometry readings $(r=0.281, p<0.001)$. Also, Bland-Altman method revealed a good agreement between both methods of thermometry as $96 \%$ of the readings were within the limits of agreement. Mean difference was $0.09^{\circ} \mathrm{C}(95 \%$ confidence interval $0.05-0.13)$. Conclusion: Axillary mercury-in-glass thermometer
\end{abstract}


and forehead non touch infra-red thermometers have a good agreement and can be used interchangeably.

\section{Keywords}

Axillary Mercury-in-Glass Thermometer, Forehead Non-Touch Infra-Red Thermometer, Bland-Altman

\section{Introduction}

Evaluation of body temperature is one of the oldest and most important step in the diagnosis of disease [1]. Accurate temperature measurement is thus a critical step in evaluating health or disease especially in children and immmunocompromised subjects [1] [2]. Inaccurate measurement may lead to improper diagnosis, wrong treatment or inappropriate intervention [2].

The temperature measured depends on the site and type of thermometer used. The most reliable means of temperature measurement is the core temperature, which is best taken at the pulmonary artery (site closest to the thermoregulatory center) [1]. Other sites for taking core temperature are the bladder, tympanic membrane, oesophagus, nasopharynx and trachea [1]. However these methods are invasive and not routinely feasible.

The Axilla, rectum and oral cavity are traditionally used to take temperatures in babies [3] Rectal thermometry is slightly invasive and poorly tolerated by children while the oral is painful, and uncomfortable, not recommended for use in patients with oral surgery, newborns or uncooperative and unconscious patients [4] Readings are also affected by consumption of hot or cold foods [4].

Types of thermometers include electronic contact thermometers, chemical thermometers, infrared thermometers and mercury-in-glass thermometers. Mercury-in-glass thermometers (MIGT) are no longer used in the developed world because of the risk of mercury contamination and poisoning.

Non touch infra-red thermometers (NTIT) are newer and measure body temperature via infrared emission from the body [4]. They are non-invasive, convenient and easier to use [2] The risk of transmission of infections is minimized with NTIT especially in the paediatric age-group in whom minimal touch and infection control is very important [1] [2].

Several studies have compared body temperatures using different thermometers [3] [4] [5] [6]. While Gasim et al. [5] and Edelu et al. [3] reported that infrared tympanic thermometers were as reliable and accurate as axillary mercury-in-glass thermometers in subjects studied. Yetman et al. [6] reported that temperatures obtained with infrared tympanic membrane thermometers did not accurately reflect an infant's rectal or axillary temperatures. Similarly, Basak et al. [4] reported a weak correlation between temperatures taken with NTIT and chemical or tympanic membrane thermometers. On the other hand, Abdulkadir et al. [7] reported that infrared tympanic thermometry readings in febrile child- 
ren better reflected rectal temperature than axillary temperature. None of these studies has actually compared thermometry readings from forehead NTIT and MIGT in the Paediatric age group. This study aims to compare this with the aim of suggesting a faster, more reliable and convenient means of taking temperature in children.

\section{Method}

Subject recruitment was carried out by the Researcher and two research assistants who had been duly trained by the Researcher after an Ethical clearance was obtained as part of a larger Poliomylitis Vaccine Trial from the University of Iloin Teaching Hospital Ethics and Research Committee. Inclusion criterial included: well baby with, aged 1 to 24 months, and consent given.All children that met the inclussion criteria were recruited over a six months period (between September 2016 and February 2017). After a clear explaination had been given to the mother/caregiver, a study proforma was administered in an interview form to obtain relevant socio-demographic features such as age of the baby, social class and immunisation history. A brief physical examination was also carried out on the babies. The elligible babies and their mothers were made to sit in the same room with a constant room temperature. Temperature of babies were taken thus:

Using the NTIT: The NTIT was held at a maximum distance of $5 \mathrm{~cm}$ from the midpoint of the forehead area until the signal tone was heard (average of $1-2$ secs). Temparatures were taken 3 times and the average reading calculated and recorded.

Using the MIGT: The MIGT was cleaned with alcohol swab and shaken before each use, to drop the mercury column to below $35^{\circ} \mathrm{C}$ and placed in the axilla for 3 - 5 minutes before the reading was taken. One reading was taken for each patient. The MIGT was then cleaned again with an alcohol swab.

\section{Data Analysis}

Data were entered into a computer and analysed with SPSS version 21.

Pearson correlation was used to determine the relationship between the two methods of temperature measurements, while Bland-Altmanmethod was used to test for level of agreement between them.Level of agreement was said to be good as if $95 \%$ of the data laid between $1.96 \mathrm{SD}$ of the mean difference between the two methods [8]. According to previous studies, mean of difference was considered good if $<0.5^{\circ} \mathrm{C}$, and satisfactory if $<0.6^{\circ} \mathrm{C}$ [9] [10].

\section{Results}

A total of Four hundred and thirty-seven (437) children were recruited from the Immunisation clinic of UITH, Amilegbe Ilorin. They were aged 1 to 24 months. The mean age and SD was $5.81 \pm 4.04$ months. Almost Fifty-four percent (53.8\%) of the children were males, while $46.2 \%$ were females. The mean birth 
weight was $3.23 \mathrm{~kg}$. While $74.1 \%$ of the children were born in a hospital, $9.8 \%$ of them were born at home.

The other socio-demographic variables are as shown in Table 1 and Table 2.

Concerning the immunization status, $94.1 \%$ of the babies had immunization at birth, 92\% had gone for the 6-week immunization visit (Table 3 ).

Not applicable were infants who were not old enough for the respective Vaccines.

The average temperatures obtained were $36.5^{\circ} \mathrm{C} \pm 0.30^{\circ} \mathrm{C}$ for NTIT and $36.59^{\circ} \mathrm{C} \pm 0.44^{\circ} \mathrm{C}$ for MGIT (Table 4 ).

Using the Pearson correlation technique, there was apositive relationship between the two methods of temperature measurements. $(r=0.281, p<0.001)$ Further details are as shown in Figure 1.

The Bland-Altman plot showed good agreement between the two methods as $96.8 \%(423 / 437)$ of the paired differences in the readings fell within the limit of agreement as shown in Figure 2. Furthermore, the width of agreement was narrow (1.7791) with a lower limit of -0.8107 (95\% CI, -0.8845 to -0.7369$)$ and an upper limit of 0.9884 (95\% CI, 0.9146 to 1.0623 ). Further details are shown in Figure 2.

Table 1. Socio-demographic variables of the study population.

\begin{tabular}{|c|c|c|}
\hline Variable & Frequency $(N=437)$ & Percent \\
\hline \multicolumn{3}{|l|}{ Age (in months) } \\
\hline Mean \pm SD & \multicolumn{2}{|c|}{$5.81 \pm 4.04$} \\
\hline Range & \multicolumn{2}{|c|}{$1.00-24.00$} \\
\hline \multicolumn{3}{|l|}{ Sex } \\
\hline Male & 235 & 53.8 \\
\hline Female & 202 & 46.2 \\
\hline \multicolumn{3}{|l|}{ Birth weight $(\mathrm{Kg})$} \\
\hline Mean \pm SD & 3.23 & \\
\hline \multicolumn{3}{|l|}{ Place of birth } \\
\hline Home & 43 & 9.8 \\
\hline Traditional birth & 21 & 4.8 \\
\hline Mission home & 45 & 10.3 \\
\hline Hospital & 324 & 74.1 \\
\hline Others & 4 & 0.9 \\
\hline \multicolumn{3}{|l|}{ Social class } \\
\hline Class I & 122 & 27.9 \\
\hline Class II & 201 & 46.0 \\
\hline Class III & 86 & 19.7 \\
\hline Class IV & 28 & 6.4 \\
\hline Class V & 0 & 0 \\
\hline
\end{tabular}


Table 2. Schema of social classification [12].

\begin{tabular}{lll}
\hline Social Class & Profession & \multicolumn{1}{c}{ Educational Attainment } \\
\hline I & $\begin{array}{l}\text { Professional, Senior public servants, Owners of large } \\
\text { business concerns, Senior military officers, large scale } \\
\text { contractors }\end{array}$ & $\begin{array}{l}\text { University graduates or } \\
\text { equivalents }\end{array}$ \\
& $\begin{array}{l}\text { Non-academic professionals e.g. Nurses, Secondary } \\
\text { school teachers, Secretaries, Owners of medium sized } \\
\text { business. Intermediate grade public servants }\end{array}$ & $\begin{array}{l}\text { School certificate holders and } \\
\text { equivalent }\end{array}$ \\
II & $\begin{array}{l}\text { Non manual skilled workers including clerks, typists, } \\
\text { telephone operators, Junior school teachers, Drivers }\end{array}$ & Grade II teachers or equivalent \\
III & Petty traders, Laborers, Messengers & Primary certificate \\
IV & $\begin{array}{l}\text { Unemployed, Full time house wives, Students, } \\
\text { Subsistence farmers }\end{array}$ & No formal education \\
V & &
\end{tabular}

Table 3. Frequency of illness, use of antipyretics and immunizations of children.

\begin{tabular}{|c|c|c|}
\hline Variable & Frequency $(\mathrm{N}=437)$ & Percent \\
\hline \multicolumn{3}{|c|}{ Illness in last 48 hours } \\
\hline Yes & 52 & 11.9 \\
\hline No & 385 & 88.1 \\
\hline \multicolumn{3}{|c|}{ Use of antipyretic drug } \\
\hline Yes & 162 & 37.1 \\
\hline No & 275 & 62.9 \\
\hline \multicolumn{3}{|l|}{ Immunization } \\
\hline \multicolumn{3}{|l|}{ At birth } \\
\hline Yes & 411 & 94.1 \\
\hline No & 26 & 5.9 \\
\hline \multicolumn{3}{|l|}{6 weeks } \\
\hline Yes & 402 & 92.0 \\
\hline No & 13 & 3.0 \\
\hline Not applicable & 22 & 5.0 \\
\hline \multicolumn{3}{|l|}{10 weeks } \\
\hline Yes & 359 & 82.2 \\
\hline No & 25 & 5.7 \\
\hline Not applicable & 53 & 12.1 \\
\hline \multicolumn{3}{|l|}{14 weeks } \\
\hline Yes & 294 & 67.3 \\
\hline No & 41 & 9.4 \\
\hline Not applicable & 102 & 23.3 \\
\hline \multicolumn{3}{|l|}{9 months } \\
\hline Yes & 102 & 23.3 \\
\hline No & 110 & 25.2 \\
\hline Not applicable & 225 & 51.5 \\
\hline
\end{tabular}


Table 4. Mean temperature measurement.

\begin{tabular}{cl}
\hline Variable & Mean \pm SD \\
\hline NTIT Temperature reading & $36.50 \pm 0.30$ \\
Axillary Temperature (MGIT reading) & $36.59 \pm 0.44$ \\
\hline
\end{tabular}

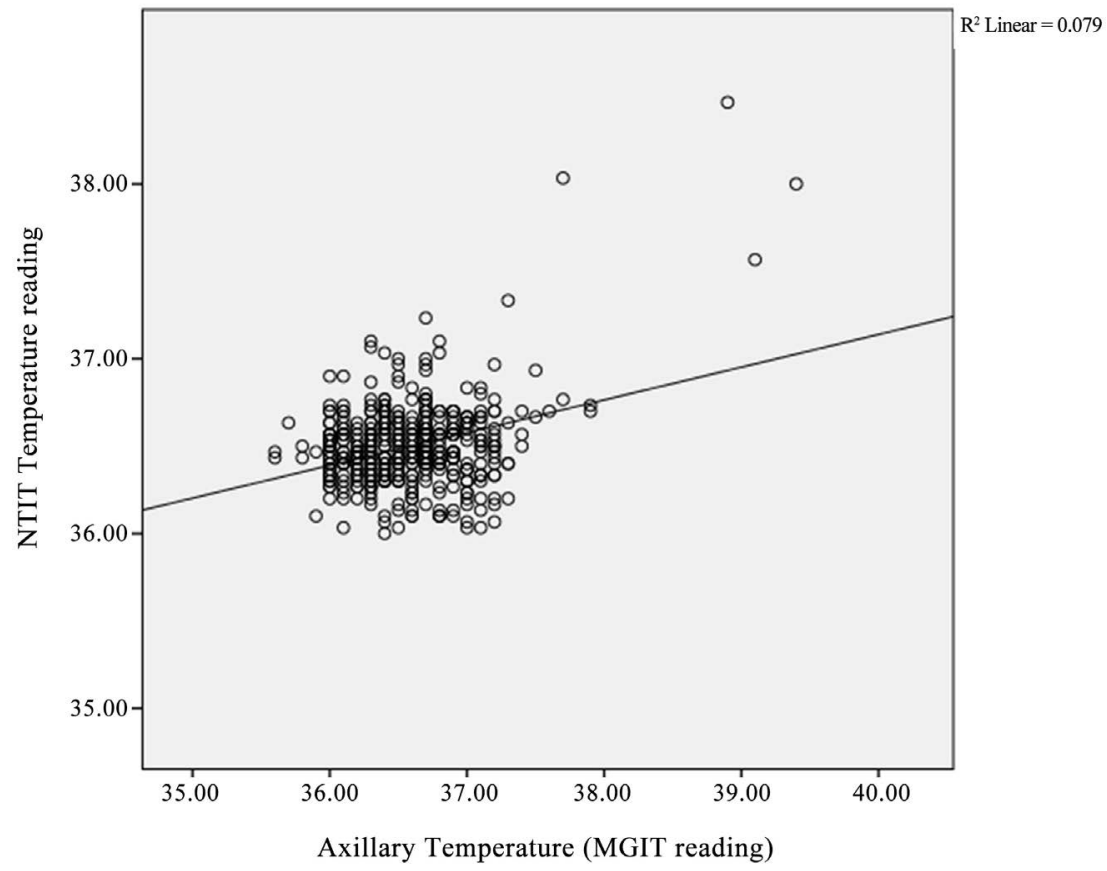

Figure 1. Correlation of the temperature reading between Non-touch infrared thermometer (NTIT) and the Axillary reading with Mercury in Glass Thermometer (MGIT).

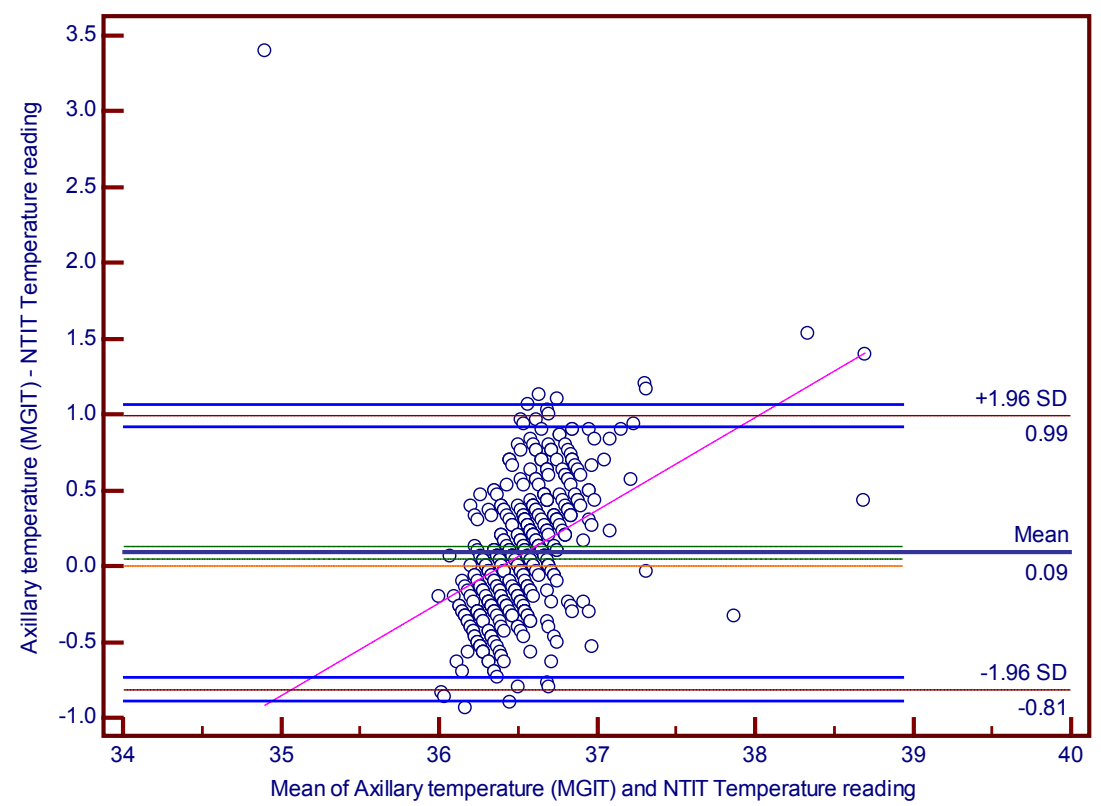

Figure 2. Bland Altman Graph showing the limit of agreement between the MIGT and NTIT readings. 


\section{Discussion}

The mean axillary temperature of $36.59^{\circ} \mathrm{C} \pm 0.44^{\circ} \mathrm{C}$ for MGIT and $36.5^{\circ} \mathrm{C} \pm$ $0.30^{\circ} \mathrm{C}$ for NTIT in this study was similar to $36.82^{\circ} \mathrm{C} \pm 0.44^{\circ} \mathrm{C}$ and $36.40^{\circ} \mathrm{C} \pm$ $0.42^{\circ} \mathrm{C}$ reported by Sollai et al. [9], but much lower than the $37.18^{\circ} \mathrm{C} \pm 0.96{ }^{\circ} \mathrm{C}$ and $37.30^{\circ} \mathrm{C} \pm 0.92{ }^{\circ} \mathrm{C}$ reported by Chiapinni et al. [11]. The reason for this disparity might be due to the fact that the current study recruited children from an immunization (well-baby) clinic while Chiapinni et al. [11] recruited patients from the Emergency unit. This is similar to the findings of Chiapinni et al. [11].

The current study finding of a positive correlation between NTIT and MGIT is consistent with the findings of Gasim et al. [5] and Edelu et al. [3]. This demonstrates a linear relationship between the temperature readings by both methods and implies that one method can be used in place of the other. The finding of a good agreement between the two thermometers is consistent with the reports of Sollai et al. [9] and Chiapinni et al. [11]; but contrary to Sethi et al. [10] and Basak et al. [4] who reported no agreement between infra-red thermometers and mercury thermometers. The difference could have been due to the fact that while the current research studied older children who were healthy, Sethi et al. [10] studied the sick neonates admitted in the intensive care unit.

Edelu et al. [3], although reported a positive correlation between the two methods of measurements, found no agreement between them. The disparity in the two studies may however be due to the fact that Edelu et al. [3] used the infra-red tympanic thermometer in the oral mode; meaning the tympanic temperature reading was converted to an approximate oral temperature reading. This process of conversion may have altered the sensitivity. Also, rectal temperature was compared with the oral temperature as against forehead and axillary temperatures used in the current study.

\section{Conclusion}

MIGT and forehead NTIT had a good positive correlation and a good agreement.

\section{Recommendation}

For speed and convenience as well as hygiene and infection control, MGIT can be safely replaced by forehead NTIT in clinical Paediatric practice. Also use of MIGT can be discontinued to reduce the concerns about environmental mercury pollution.

\section{Limitation of the Study}

The neonatal age group was not included in the study. Also, Tympanic temperature, which is a better estimate of the core temperature was not done in this study and may be a line of future research in healthy children. 


\section{Funding}

No specific Grants available for this work.

\section{Conflicts of Interest}

The authors declare no conflicts of interest regarding the publication of this paper.

\section{References}

[1] Thye, S.L., Sabirin, J. and Bakri, R. (2012) Infrared Thermometer. Ministry of Health, Putrajaya.

[2] National Institute for Health Research (2015) Non-Contact Infrared Thermometers. Diagnostic Evidence Co-Operative.

https://www.community.healthcare.mic.nihr.ac.uk/reports-and-resources/reports-0 025.pdf

[3] Edelu, B.O., Ojinnaka, N.C. and Ikefuna, A.N. (2011) Fever Detection in under 5 Children in a Tertiary Health Facility Using the Infrared Tympanic Thermometer in the Oral Mode. Italian Journal of Pediatrics, 37, 8. https://doi.org/10.1186/1824-7288-37-8

[4] Basak, T., Aciksoz, S., Tosun, B., Akyuz, A. and Acikel, C. (2013) Comparison of Three Different Thermometers in Evaluating the Body Temperature of Healthy Young Adult Individuals. International Journal of Nursing Practice, 19, 471-478.

[5] Gasim, G.I., Musa, I.R., Abdien, M.T. and Adam I. (2013) Accuracy of Tympanic Temperature Measurement Using an Infrared Tympanic Membrane Thermometer. BMC Research Notes, 6, 194. https://doi.org/10.1186/1756-0500-6-194

[6] Yetman, R.J., Coody, D.K., West, M.S. and Brown, M. (1993) Comparison of Temperature Measurements by an Aural Infrared Thermometer with Measurements by Traditional Rectal and Axillary Techniques. Journal of Pediatrics, 122, 769-773. https://doi.org/10.1016/S0022-3476(06)80024-7

[7] Abdulkadir, M. and Johnson, W. (2013) A Comparative Study of Rectal, Tympanic and Axillary Thermometry in Febrile Children under 5 Years of Age in Nigeria. Paediatrics and International Child Health, 33, 165-159. https://doi.org/10.1179/2046905513Y.0000000066

[8] Bland, J.M. and Altman, D.G. (1999) Measuring Agreement in Method Comparison Studies. Statistical Methods in Medical Research, 8, 135-160.

[9] Sollai, S., Dani, C., Berti, E., Fancelli, C., Galli, L., de Martino, M., et al. (2016) Performance of a Non-Contact Infrared Thermometer in Healthy Newborns. BMJ Open, 6, e008695.

[10] Sethi, A., Patel, D., Nimbalkar, A., Phatak, A. and Nimbalkar, S. (2013) Comparison of Forehead Infrared Thermometry with Axillary Digital thermometry in Neonates. Indian Pediatrics, 50, 1153-1154. https://doi.org/10.1007/s13312-013-0302-y

[11] Chiappini, E., Sollai, S., Longhi, R., Morandini, L., Laghi, A., Emilia Osio, C., et al. (2011) Perfomance of Non-Contact Infrared Thermometer for Detecting Febrile Children in Hospital and Ambulatory Settings. Journal of Clinical Nursing, 20, 1311-1318. https://doi.org/10.1111/j.1365-2702.2010.03565.x

[12] Oyedeji, G. (1985) Socio-Economic and Cultural Background of the Hospitalized Children in Ilesha. Nigerian Journal of Paediatrics, 12, 111-117. 